\title{
EVALUATION OF TOPICAL OZONE THERAPY ON HEALING OF MANDIBULAR BONY DEFECTS Mohamed $\mathrm{S} \mathrm{T}^{1} B D S$, Sharara A A ${ }^{2} P h D$, Ragab $\mathrm{H} \mathrm{R}^{3} P h D$, Zahran $N M^{4} P h D$
}

\begin{abstract}
:
Introduction: Bone defects are commonly found in oral cavity, they may have functional or esthetical problems that need surgical intervention. The emergence of ozone therapy seems to be a promising future in different dental modalities that may be effective in treating bony defects.

Objective: To evaluate histologically the effect of topical administration of ozone therapy; on healing of experimentally-induced mandibular bone defects; in dogs.

Materials and methods: A split mouth design was carried out below the 4th mandibular premolar of six healthy mongrel dogs. A total of 12 bony defects were surgically created. After reflecting the mucoperiosteal flap, the defects in the right side were treated with ozonated gel and those in the left side did not receive any treatment. Two dogs were sacrificed after 2, 6, 12 weeks. Samples were dissected and prepared for histological evaluation
\end{abstract}

Results: The study revealed that using ozone gel in bony mandibular defects accelerates the onset of new bone formation and increases vascularization at the injured site.

Conclusion: Ozone is a beneficial agent to avoid possible complications and to have better chance for soft and hard tissue healing.

Key Words: ozone gel, bony defect, histological examination.

1. B.D.S. Faculty of Dentistry, Alexandria University

2. Professor of Oral \& Maxillofacial Surgery, Faculty of Dentistry, Alexandria University

3. Assistant Professor of Oral and Maxillofacial Surgery, Faculty of Dentistry, Alexandria University

4. Lecturer of Histology and cell Biology, Faculty of Medicine, Alexandria University

\section{INTRODUCTION}

Bone defects are commonly found in oral cavity and are often the result of traumatic injury to the teeth, bone, periodontal disease, tumors or cancer and diseases affecting pulp or congenital defects (1).

The defect may have functional, esthetical problems (2) or loss of jaw structure, resulting in impaired mastication and speech (3).

As a result of all these problems, reconstructive surgical intervention may be addressed (4).

Ozone therapy has a proven clinical efficiency in treating bacterially, fungally, virally produced diseases due to its strong bactericidal, fungicidal, virostatic properties, reactivating the immune system through macrophage activation and cytokines release which in turn boost the immune system (5), ozone is an allotropic form of oxygen which contains three atoms (O3), it occurs naturally as a gas in a concentration of 10-20 parts per million (6).

Moreover, Ozone therapy will speed healing and help remineralization of bone, improved bone density, improve tissue oxygenation, directly enhances antioxidant defences, disinfect \& sterilize infected wounds and modulate excessive humoral "antibody" activity (7).

Current ozone uses a mixture of ozone gel and pure oxygen, with today's medical ozone generators which regulate the flow of medical grade $\mathrm{O} 2$ through high voltage tubes which is capable of producing pure ozone-oxygen mixtures in precise dosages (8). Ozone gel can be considered as an effective medication in alveolitis treatment and effective one for inflammation $(8,9)$.

In addition, Ozone is the best healing material owing to having an oxidizing power many times that of chlorine (10). It degrades hydrocarbons accumulated within the cells, and hence lightens the toxic weight of the body, rendering the tissues more resistant to infection, aging and increases its capability to regenerate and divide (11).

The aim of this study was to evaluate the histological effect of topical administration of ozone therapy on healing of experimentally-induced mandibular bone defects in dogs.

\section{MATERIALS AND METHODS}

This study was agreed by ethical committee.

The experimental animals:

The present study was performed on six adult male healthy dogs with weight ranging from $10-15 \mathrm{~kg}$. All dogs were kept under the same nutritional and environmental conditions in the animal house of the Physiology Department, Faculty of Medicine, Alexandria University.

\section{The study group:}

Six defects were treated with ozone therapy which was applied topically in the form of gel inside the defect at the right side of the mandible.

\section{The control group:}

Six defects were under the same procedure as the study group at the left side of the mandible but they did not receive any treatment.

\section{Materials:}

Ozonated gel (Ozoxlive health products manufacturing company, Konya, Turkey) contains pure olive oil, ultra pure ozone, no preservatives and no stabilizers or stabilizers in cold temperature which becomes ointment by the use of Ext 120 (Longevity extra 120, longevity co. Canada.) advanced ozone generator. 


\section{Preoperative care:}

Animals were kept individually in cages and fed a standard diet twice daily with water. Animals were given antibiotics, spiramycin (Rovapex provided by apox phara co. 13, AFL atoun st. Heliopolis, Cairo, Egypt.) (75 mg/kg) and metronidazole (Flagyl provided by santiaventis Co. 3, EL Massaneh. St. zietoun, Cairo, Egypt.) (12.5 mg/kg) orally three days before surgery.

\section{The surgical procedure:}

After food and water deprivation for 12 hours each animal was anaesthetized generally via intravenous injection of triopentone sodium. (Barbiturate: provided by Glazer exports co. Dinshaw Waccha, India.)

The area of incision was disinfected with betadine ${ }^{\circledR}$ (Povidone-iodine u.s.p $10 \%$ w/v. NILE co for pharmaceutical and chemical industries, Cairo, A.R.E.) antiseptic solution.

The animals were placed on the left lateral recumbency position and a full mucoperiosteal flap was made in the region of the mandibular right 4 th premolar by an incision apical to the mucogingival line in the right disto-mesial direction performed on mesial and distal margins of the same tooth.

The flap was reflected and a defect of approximately $2 \times 3 \times 3 \mathrm{~cm}$ will be created below the roots of 4 th premolar with low speed trephine bur drill no. 50 with constant irrigation with $(0.9 \%$ saline solution).

Both sides of the mandible were used as study (right side) and control (left side).

In the study group (right side) the defect was filled with ozonated gel (Figure 1) while in the control group (left side) the cavity was not filled with any material.

Closure of the mucoperiosteal flaps in both groups with interrupted sutures (vicryl 3-0).

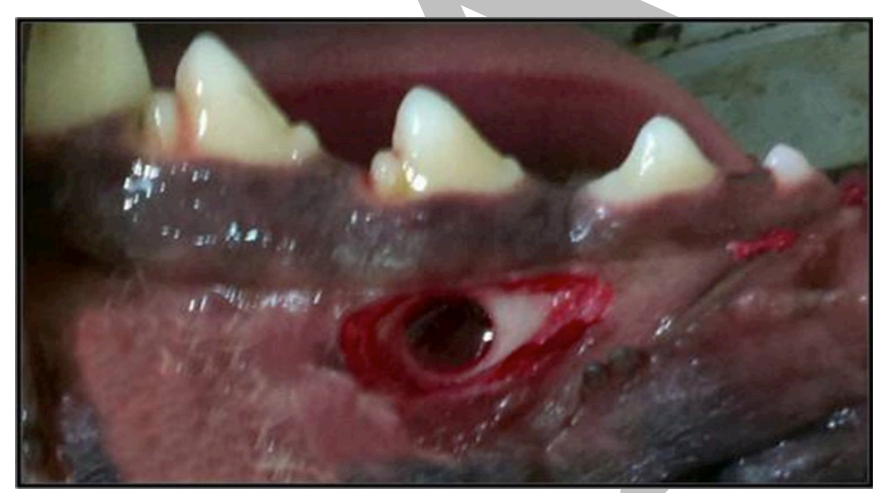

Fig. 1: Mandibular bony defect filled with ozonated gel.

\section{Post-operative care:}

Animals were given the same course of antibiotics [spiramycin $(75 \mathrm{mg} / \mathrm{kg})$ and metronidazole $(12.5 \mathrm{mg} / \mathrm{kg})$ ] for 3 days after surgery every $8 \mathrm{~h}$.

Diclofenac sodium (Cataflam: NSAID, provided by Novartis, Elsawah st, Amiria, Cairo, Egypt.) tablets every $8 \mathrm{~h}$ were given as analgesic and anti-inflammatory for 3 days. The dogs were kept on soft diet for the first week.

\section{Post-operative follow-up:}

Was carried as follows;

\section{Clinically}

Evaluation of any reactions or complications was performed including: Infection, wound dehiscence, edema or hematoma.

\section{Histologically}

Two dogs were sacrificed at intervals 2,6,12 weeks.

Two specimens from each animal were obtained bilaterally and prepared for histological study and prepared to be examined by the light microscope.

Preparation of paraffin sections and reactions - Segments of the biopsies were fixed in 10\% neutral buffered formalin.

The fixation of the specimens was followed by washing, decalcification, washing, dehydration, clearance, infiltration, embedding, cutting, mounting and stains preparation.

The stains used in this study were

1. Haematoxylin and Eosin stain (12).

2. Trichrome stain (12).

\section{RESULTS}

\section{Clinical results}

There was absence of any reactions or complications including: Infection, wound dehiscence, edema or hematoma through the study period.

\section{Histological results}

\section{Haematoxylin and Eosin}

Examination of sections revealed that

\section{Two weeks post-operative period}

- The study group, (right side) - (ozonated gel); showed that there was filling of the defect area by dense irregular connective tissue fibers with increased vascularization. (Figure 2A)

- The control group, (left side); showed that there have been areas of incomplete filling of defect area by minimal amount of irregular C.T fibers, presence of blood vessels with some perivascular cellular infiltration and remnant of bone debris detected. (Figure 2B)

\section{Six weeks post-operative period}

- The study group revealed regular organization of connective tissue fibers forming bone trabeculae and calcified materials deposition with wide and variable cavities enclosing. (Figure 3A)

- The control group showed irregular organization of collagen fibers forming irregular trabecular and enclosing wide irregular cavities with debris of old bone. (Figure 3B)

- Also congestion of blood vessels was noticed.

- On the other hand failure of complete obliteration of defect area with incomplete areas of connective tissue fibers was detected in another specimen. 


\section{Twelve weeks post-operative period}

- $\quad$ The study group; showed complete fusion between old bone and new bone formation filling the defect area with small cavities with mild congestion of blood vessels. (Figure 4A)

- The control group; showed the defect area filled by newly calcified material, irregular bone trabeculae separated by wide cavities. (Figure 4B)

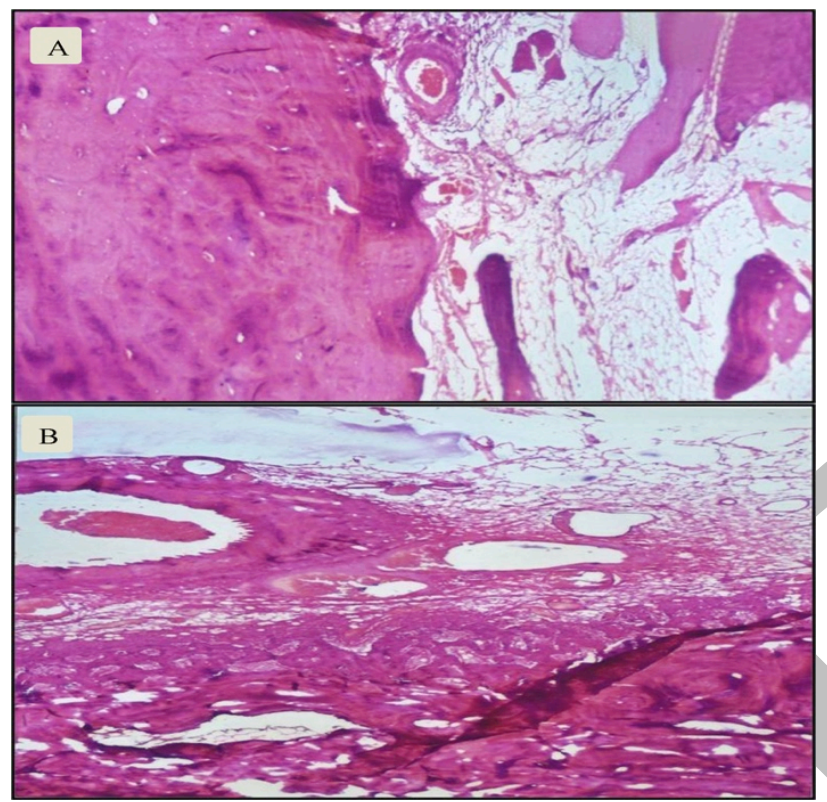

Fig. 2: (A) Light micrograph study group (I) section of bone defect after 2 weeks. (H\&E stain). (B) Light micrograph control group $(\mathrm{G})$ bone defect after 2 weeks.

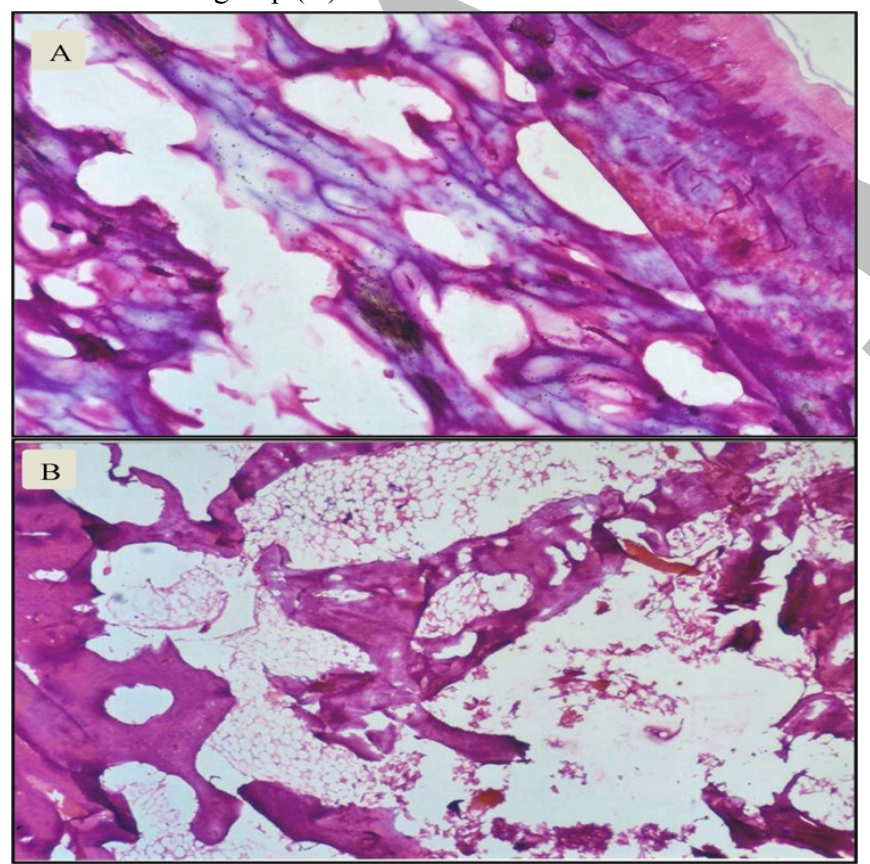

Fig. 3: (A) Light micrograph study group bone defect after 6 weeks (Right side). (H\&E stain). (B) Light micrograph control group bone defect after 6 weeks (left side).

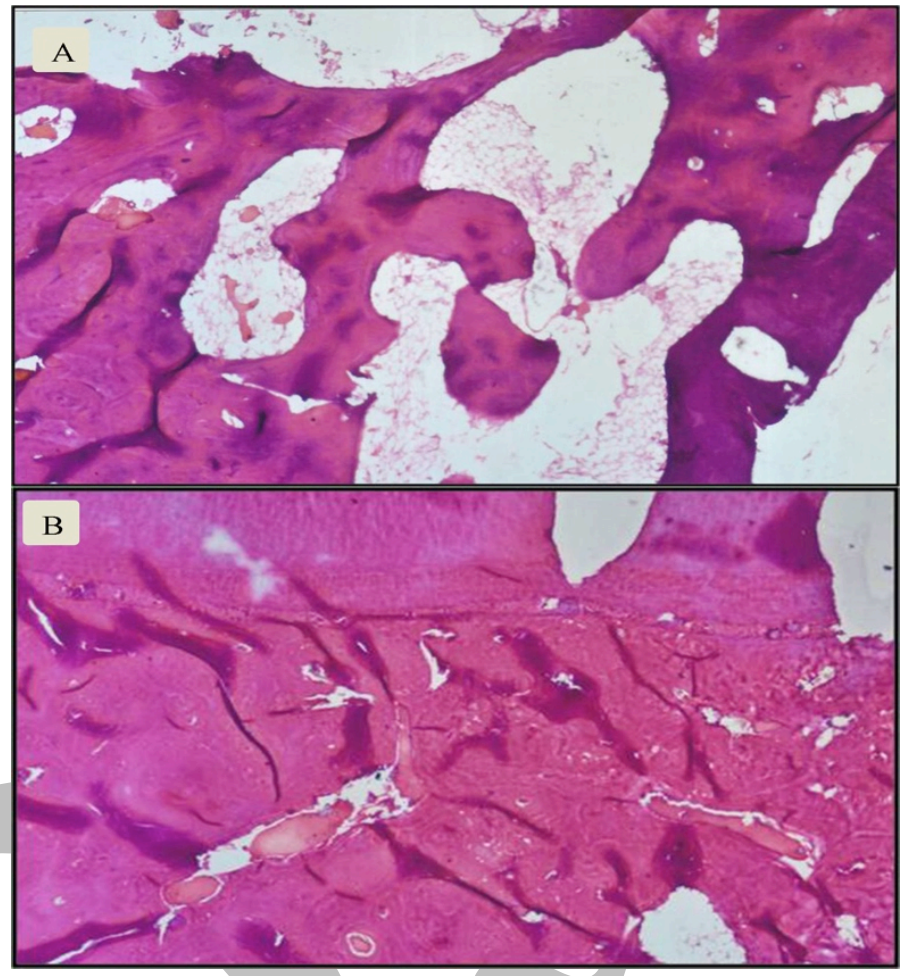

Fig. 4: (A) Light micrograph study group bone defect after 12 weeks (Right side). (H\&E stain). (B) Light micrograph control group bone defect after 12 weeks (left side).

\section{Trichrome stain}

\section{Two weeks post-operative period}

- The study group; showing condensation of connective tissue fibers filling the defect area.

- The control group; showed that there was incomplete filling of the defect area by irregular sparse connective tissue fibers.

\section{Six weeks post-operative period}

- The study group; depicting formation of newly calcified material and increased collagen formation surrounding wide irregular cavities.

- The control group; showing the defect area filling wide cavities, irregular and incomplete formation of bone trabeculae.

\section{Twelve weeks post-operative period}

- The study group; showing complete fusion and obliteration of defect area by newly calcified material and regular arrangement of collagen fibers to form immature haversians. (Figure 5A)

- The control group; revealing incomplete healing of defect area with formation of wide irregular calcified material with variable wide cavities. (Figure 5B) 


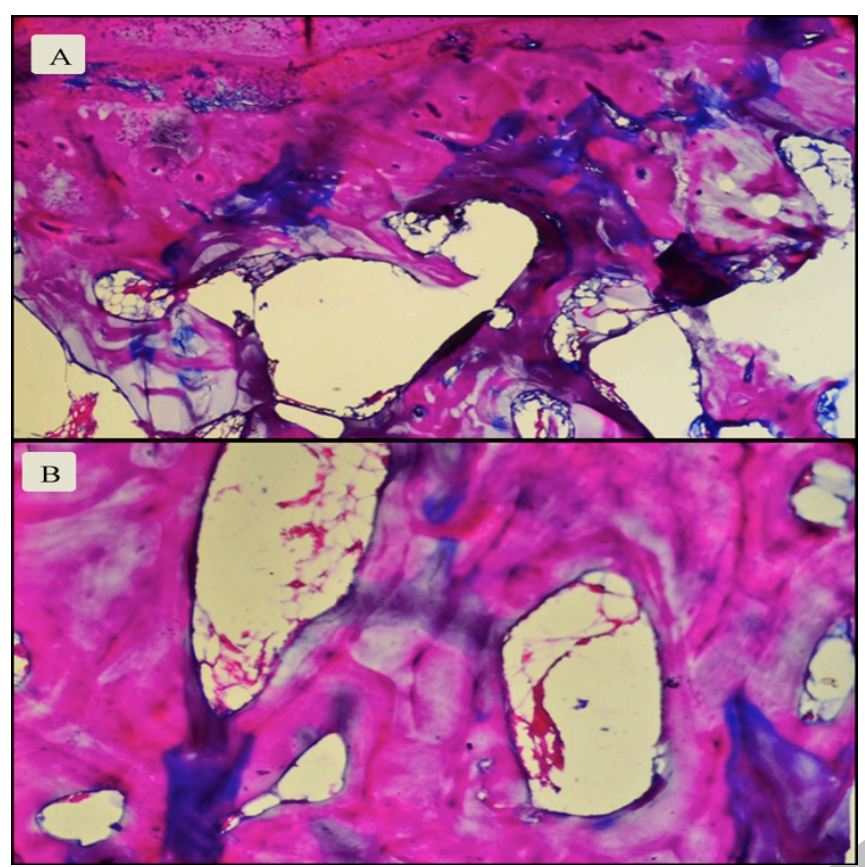

Fig. 5: (A) Light micrograph study group bone defect after 12 weeks (Right side). (Tri chrome stain).

(B) Light micrograph control group bone defect after 12 week (left side).

\section{DISCUSSION}

Ozone therapy isn't an entirely new concept in dentistry, previous researches and medical reviews have discussed the importance of ozone in replacing antiseptic agents used against dental infections (13).

Some animals, however, more closely resemble humans than others. In particular, with regard to bone density, the characteristics of human bone are best approximated by the properties of dog bone that's why dogs have been chosen in this experimental study (14).

In this study immediately after application of the ozone gel in the bony defect decreasing of bleeding was decreased at the wound area. This finding was in agreement with Phillipi in 1997 (15) who reported that the ozone acts as a therapeutic agent through raising haemostasis.

This study revealed by using ozone gel inside mandibular bony defect that from the 2 nd to the 12 th post operative week either by $\mathrm{H} \& \mathrm{E}$ stain or trichrome stains, there was an increase in the bone density (well organized mineralized bone) in both study and control groups, but the increase in bone density was greater in the study group than in the control group. Increasing of vascularity also was found greater in the study group than in the control group.

This is supported by previous studies which concluded that ozone therapy has a positive influence on bone metabolism and improvement of reparative process in bone (16).

These histological findings are in agreement with Silivia, et al in 1995 (17), Hendy in 2009 (18), Kayed in 2009 (19), Hunter in 1995 (20) and Hebal in 1989 (21) who reported diminished time of healing and a significant increase in bone density in defects treated with ozonated gel.
Although, Kotze et al in 2014 (22) on evaluation of the role of ozone in the advancement of alveolar bone healing in the absence of bone pathology in the baboon that doesn't show healing following trauma. He found that there is alack of evidence of the effect of ozone on bone regeneration.

Many studies proved the good therapeutic effect and healing power of ozone even in pathological conditions: as in diabetic El-Kazzaz in 2011 (23), who has found a positive effect on bone formation and thus preventing severe bone resorption as a complication of diabetes.

Also the effect in the periodontium Sorokina \& Lukinych in 1997 (24) and Nagayoshi et al in 2004 (25) reported that the ozone has a pronounced anti-inflammatory effect, reducing oral micro-organisms, enhancing greater gain in the clinical attachment level and decreasing the pocket depth.

From this study, it is clear that ozone is considered a good therapeutic agent of great benefits in the short or long terms, this finding is in agreement with many investigators who reported that ozone is a new therapeutic modality which had a potent antimicrobial power, along with its capacity to stimulate the circulatory system and modulate the immune response, making it a therapeutic agent of choice in the treatment of over 260 medical pathologies (26).

\section{CONCLUSIONS}

- Using ozonated gel for bone regeneration in the treatment of osseous defects is a potential treatment and fastens the healing and increase vascularization leading to acceleration of the onset of new bone formation.

- Ozonated gel is one of the best healing material owing to its various properties. So it is adviced to be used to avoid possible complications and to have better chance for soft and hard tissue healing.

\section{CONFLICT OF INTEREST}

The authors declare that they have no conflicts of interest.

\section{REFERENCES}

1. Kruger F. Reconstruction of bone and soft tissue in extensive facial defects. J Oral Maxillofac Surg 1982; 40: 717-20.

2. Kluft O, van Dop F. Mandibular ameloblastoma (resection with reconstruction): a case report with concise review of the literature. Arch Chiv Nearl 1970; 8: 114

3. Zhao Y, Zhang W, Zhao JH. Reconstruction of intra oral defects after cancer surgery. J Oral Maxillofac Surg 2001; 59: 1142-6.

4. Blackwell KE, Buchbinder D, Biller HF, Urken ML. Reconstruction of massive defects in the head and neck: the role of simultaneous distant and regional flaps. Head Neck 1997; 19: 620-8.

5. Bocci VA. Tropospheric ozone toxicity vs. usefulness of ozone therapy. Arch Med Res 2007; 38: 265-7.

6. Hunter B. Ozone application: An In-Depth discussion. Health Freedom News 1995; 15: 189-96.

7. Viebahn R. The use of ozone in medicine. 2nd ed. 
Heidleberg, Germany: Karl F. Hanf publishers GmbH \& co., 1987.

8. Harken M. Factors influencing the ozone inactivation of enteric viruses in effluent. Ozone: Science and Engineering 1985; 6: 235-43.

9. Menendez CO, Martinez ME, Claverat T. Application of ozonized oil in the treatment of alveolitis, 2nd international symposium on ozone applications. Havana, Cuba: 1997.

10. Knoch G, Roschke W, Klug W. Ozone/oxygen therapy in proctology. Ozona Chrichten 1987; 6: 635-41.

11. Viebahn-hunster R. Ozone therapy: the underlying therapeutically concept and models of efficacy. Erfahr ungsheilkunde 1991; 40: 871-24.

12. Ashour E. Healing of osseous defects using demineralized freeze-dried bone with resorbable and non resorbable membranes. M. Sc. Thesis. Oral Surgery Department, Faculty of Dentistry, Alex University. 2000.

13. Huth KC, Jakob FM, Saugel B, et al. Effect of ozone on oral cells compared with established antimicrobials. Eur J Oral Sci 2006; 114: 435.

14. Aerssens J, Boonen S, Lowet G, Dequeker J. Interspecies differences in bone composition, density, and quality: potential implications for in vivo bone research. Endocrinology 1998; 139: 663-70.

15. Pillipi A. Ozone in oral surgery. Current status and prospects. Ozone Sci Engin 1997; 19: 387-93.

16. San Severino ER. Knee-joint disorders treated by oxygen-ozone therapy. Euorpa Medico Physica 1989; 25: $163-70$.

17. Silivia M, Olgac, Odalys R, Labaut D, Odalys C, Laura E, Wilfredo D. application of ozonized oil in the treatment of infected ridicule conduits, Ozone research center. National center for scientific research,. Elpidio Berovides Polyclinic 1995; 3: 84-9.

18. Hendy Z. Effect of ozone gel and bioactive glass with ozone gel on healing of bone defects on experimental animals. M.Sc. Thesis. Faculty of Dentistry, Alexandria University. 2009.

19. Kayed S. Evaluation of the effect of ozone gel after surgical removal of impacted lower third molar. M.Sc. Thesis. Faculty of Dentistry, Alexandria University. 2009.

20. Hunter B. Ozone application: An in-Depth Discussion. Health Freedom News 1995; 14: 189-96.

21. Hebal MB. Advances in plastic and reconstructive surgery. Chicago YBMB 1989; 5: 244.

22. Kotze M, Bütow KW, Olorunju SA, Kotze HF. Ozone treatment of alveolar bone in the Cape Chacma baboon does not enhance healing following trauma. J Maxillofac Oral Surg 2014; 13: 140-7.

23. El Kazzaz N. Evaluation of the effect of ozone administration in diabetic induced rats. M.Sc. Thesis. Faculty of Dentistry, Alexandria University. 2009.

24. Sorokina S, Lukinych L. Ozone Therapy as a Part of a Complex Treatment of a Paradontium Disease. The Medical Academy of Nizhni Novgorod, Russia. 2nd international symposium on ozone application. Havana,
Cuba. 1997.

25. Nagayoshi M, Fukuizumi T, Kitamura C, Yano J, Terashita M, Nishihara T. Efficacy of ozone on survival and permeability of oral microorganisms. Oral Microbiol Immunol 2004; 19: 240-6.

26. Nogales CG, Ferrari PH, Kantorovich EO, LageMarques JL. Ozone therapy in medicine and dentistry. J Contemp Dent Pract 2008; 9: 75-84.

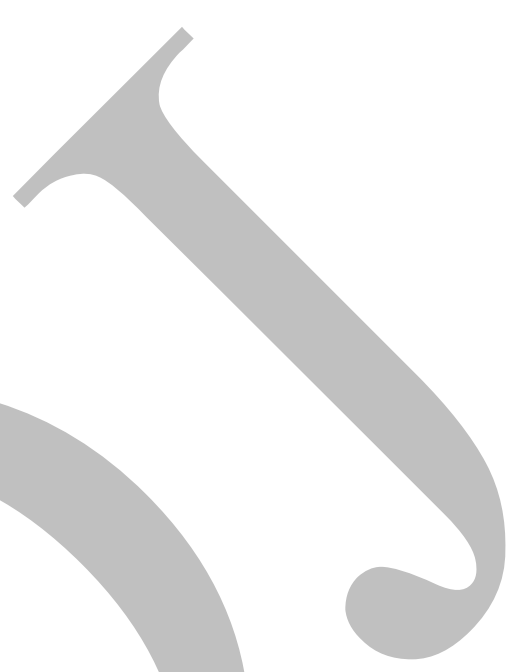

